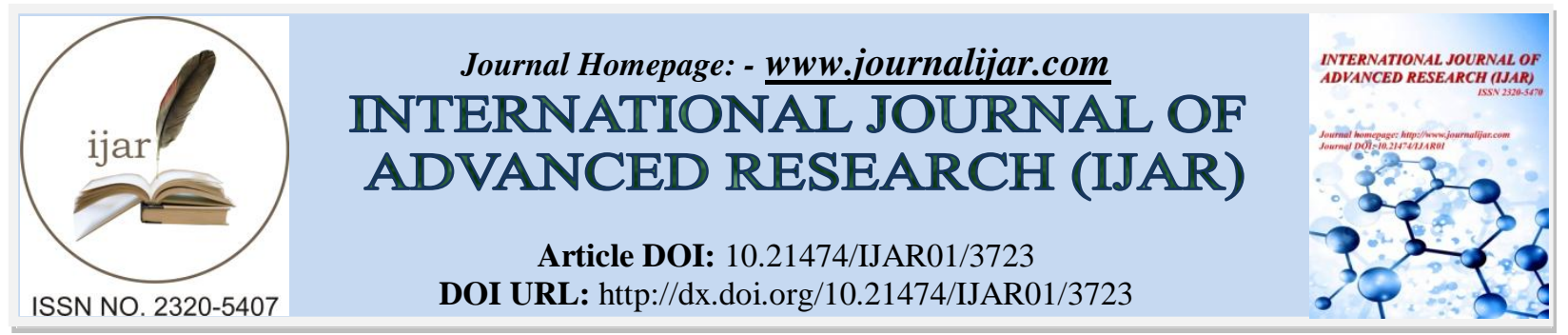

RESEARCH ARTICLE

\title{
ATYPICAL CLUB FOOT: EARLY DIAGNOSIS \& TREATMENT BY MODIFIED PONSETI TECHNIQUE GOVERMENT MEDICAL COLLEGE JAMMU.
}

\author{
Dr. Kanav Mahajan ${ }^{1}$, Dr. Sanjeev Gupta ${ }^{2}$, Dr. Mohinder Singh Chib ${ }^{3}$ and Dr. Rahul Mahajan ${ }^{1}$. \\ 1. Junior Resident Postgraduate Department of Orthopaedics GMC Jammu. \\ 2. Associate Professor Postgraduate Department Of Orthopaedics GMC Jammu. \\ 3. Senior Resident Postgraduate Department Of Orthopaedics GMC Jammu.
}

\section{Manuscript Info}

Manuscript History

Received: 15 January 2017

Final Accepted: 09 February 2017

Published: March 2017

\begin{abstract}
Atypical clubfoot is a clinical type of idiopathic clubfoot that requires early detection and modification in the Ponseti treatment. The goal of treatment is to reduce or eliminate its 4 components so that the patient has a near functional foot and lives a normal life: We had 20 patients with 20 idiopathic atypical clubfoot deformity .Clinically, atypical clubfeet is defined as having rigid equinus, severe plantar flexion of all metatarsals, a deep crease above the heel, a transverse crease in the sole of the foot, short foot and a short and hyperextended first toe. Correction was achieved in all patients by modifying the Ponseti manipulation and casting technique. The mean number of casts that were applied to obtain correction was 8 (range four to nine casts). Tenotomy was done in all feet. Finally all the feet were considered clinically cured. Modified Ponseti method is an effective treatment for congenital idiopathic atypical clubfoot and reduces the need for corrective surgery .
\end{abstract}

Copy Right, IJAR, 2017,. All rights reserved.

\section{Introduction:-}

During the course of treatment of idiopathic clubfoot by ponseti technique all feet show resistance to treatment. These feet have typical features like short foot, smaller great toe, deep planter crease. These feet are not usually identified initially but over the course of treatment these features become more prominent. Turco (1994) advised against surgery in these feet. He classified them as atypical clubfeet.Ponseti et al.(2006)advised about change in his standard protocol in these feet. We performed these modified Ponseti technique of manipulations and casting to see if this modified treatment would result in correction and maintenance of the correction for these atypical clubfeet.

\section{Materials and methods:-}

20 patients with 20 clubfeet were chosen. They were atypical clubfeet as they showed resistance to standard casting technique and had following features: feet were short and stubby, deep crease present over sole of foot, deep crease above the heel, severe equinus and supination,forefoot in adduction and planterflexion of all metatarsals.(figure 1) 

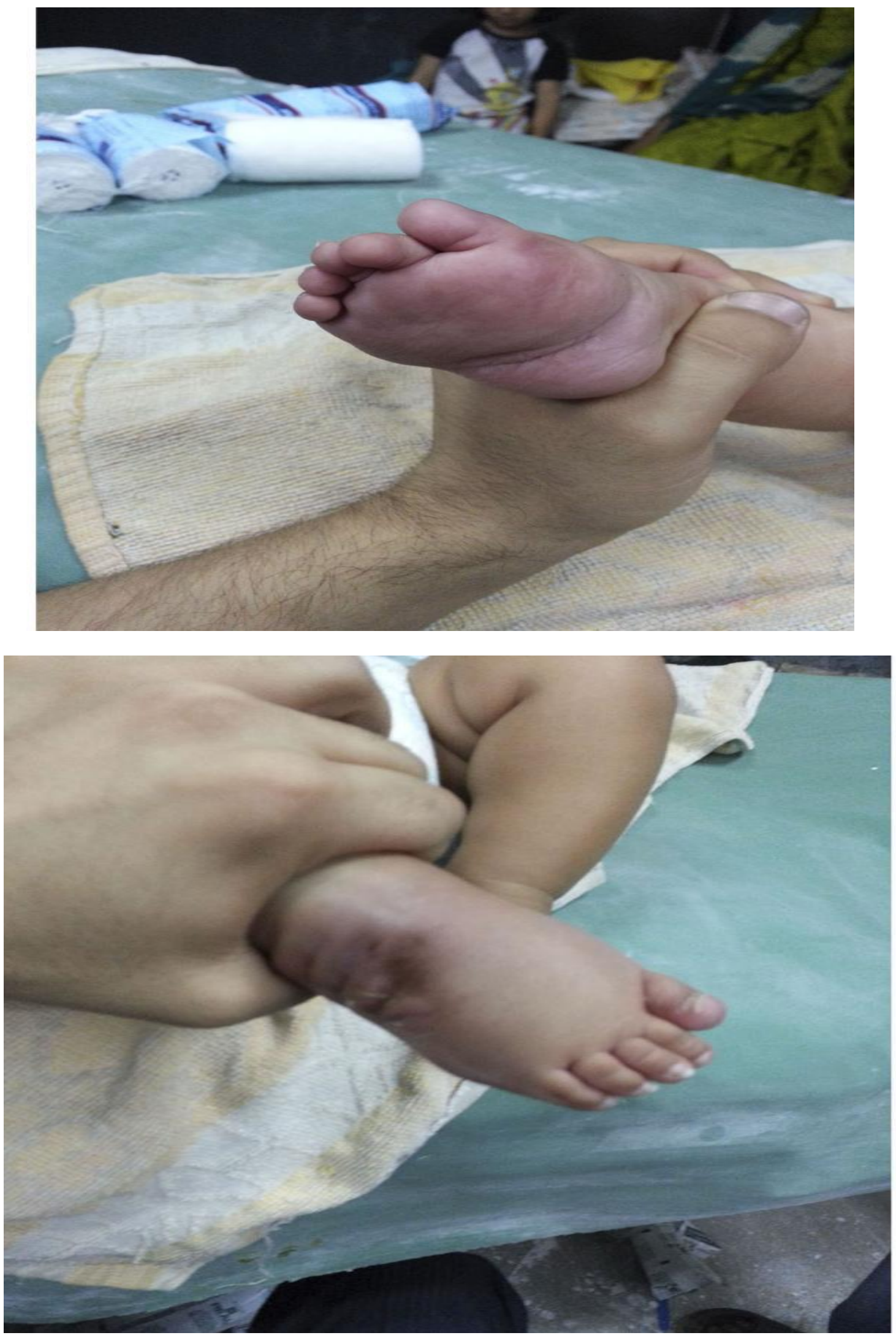
There were 9 boys and 7 girls. Average age of patients was 3 months (range 1 - 5 months). Treatment had been started in our hospital and from outside by applying plaster casts. We excluded syndromic clubfoot $\&$ clubfoot associated with neuromuscular disorders. The average follow-up was for $1 \&$ half years (range 1 to 3 years). In all these patients plaster casts were applied. In all these cases standard ponseti technique was modified. Correct identification of talar head is essential. It is done by moving index finger and thumb down lateral malleoli and then grasping the head of talus. With the other hand forefoot is abducted which causes movement at Talo-calcaneonavicular joint and thus in the correct identification of talar head.

Abduction is done by putting thumb on lateral aspect of head of talus. Index finger of same hand is put behind lateral malleolus. Using thumb and index finger of other hand abduction is done.(figure 2)

Abduction is done upto 40 degrees only. Standard abduction of 70 degrees is not done. Abduction is always kept less than 40 degrees. Abduction beyond 40 leads to abduction at tarsometatarsal joints and thus disruption of this joint. While abduction is being done, the foot usually come $\mathrm{s}$ into alignment with the long axis of the leg. This usually leads to slipping of cast which may cause foot edema and skin excoriation. To prevent this we applied the cast with the knee bent to 110 degrees. To prevent excessive cast behind the knee, we applied slab of cast anteriorly on the knee to strengthen the cast. A similar slab was applied behind ankle. When desired abduction was obtained, the metatarsals were still severely planterflexed. Here another modification was performed. Thumbs of both hands were placed under the heads of 1 st and 5 th metatarsals. Index fingers of both hands were placed dorsally over the talar head and dorsiflexion of metatarsals and ankle was performed. (Figure 3) Tenotomy was performed in all cases.

(Figure 4)

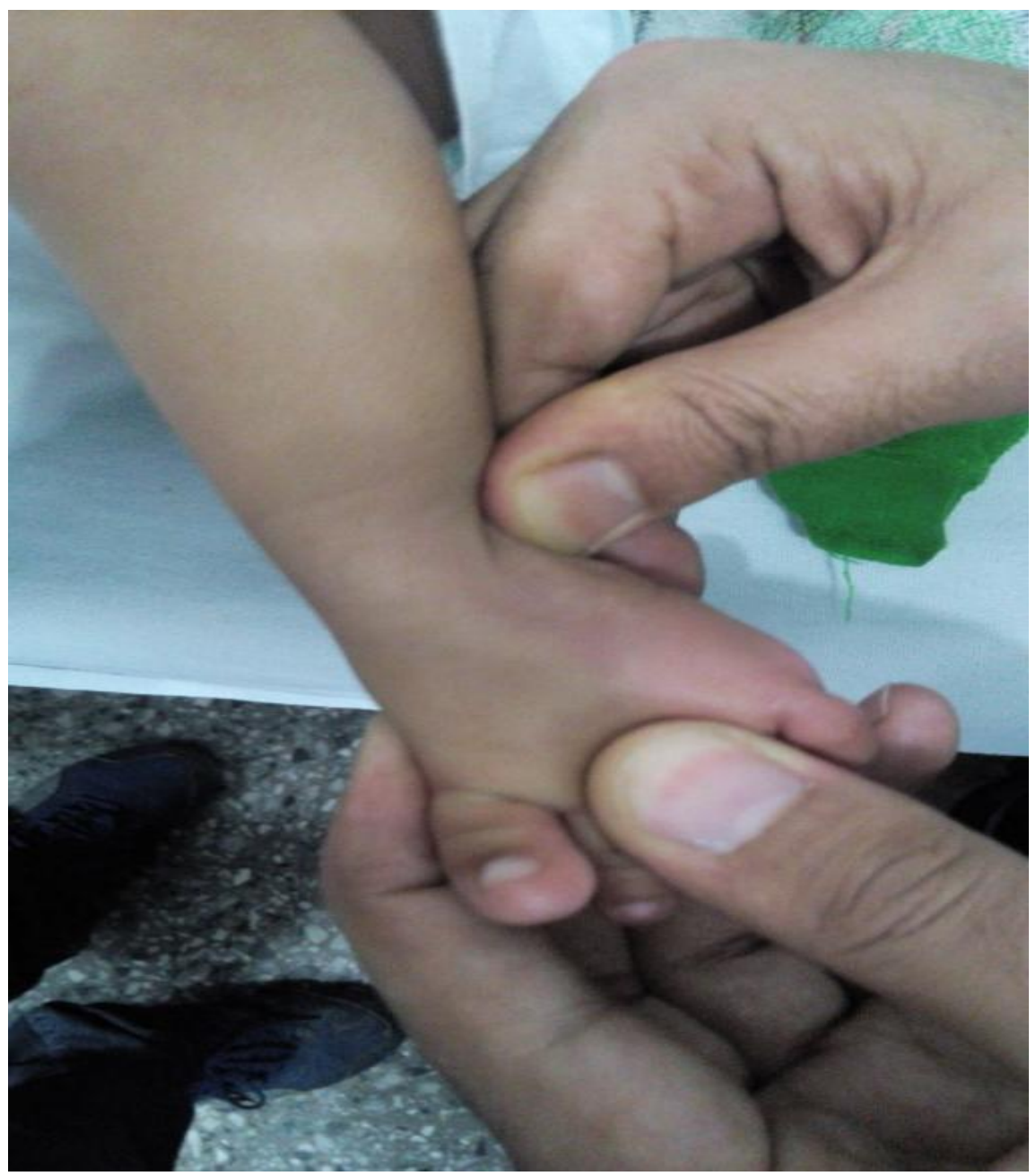




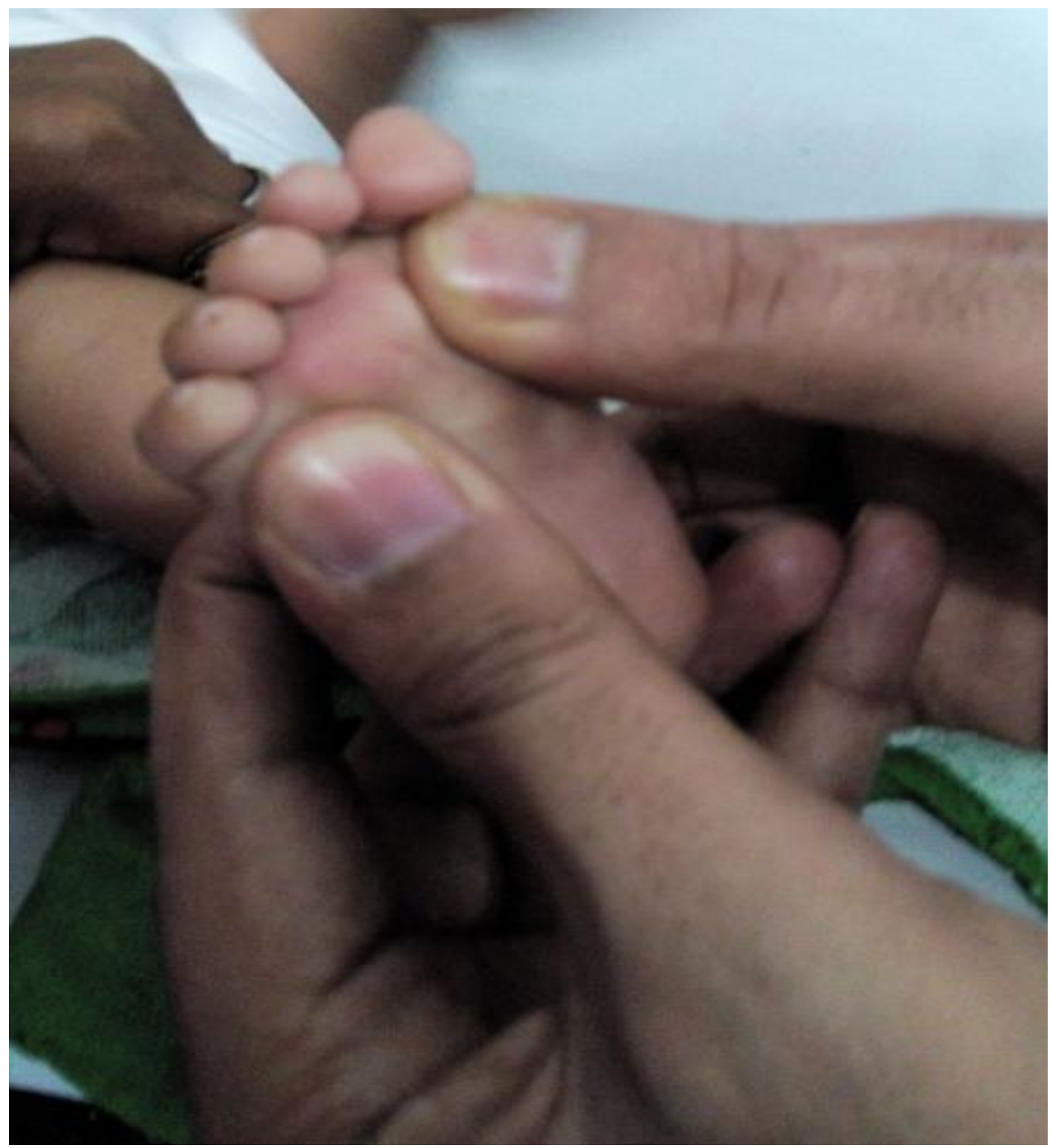



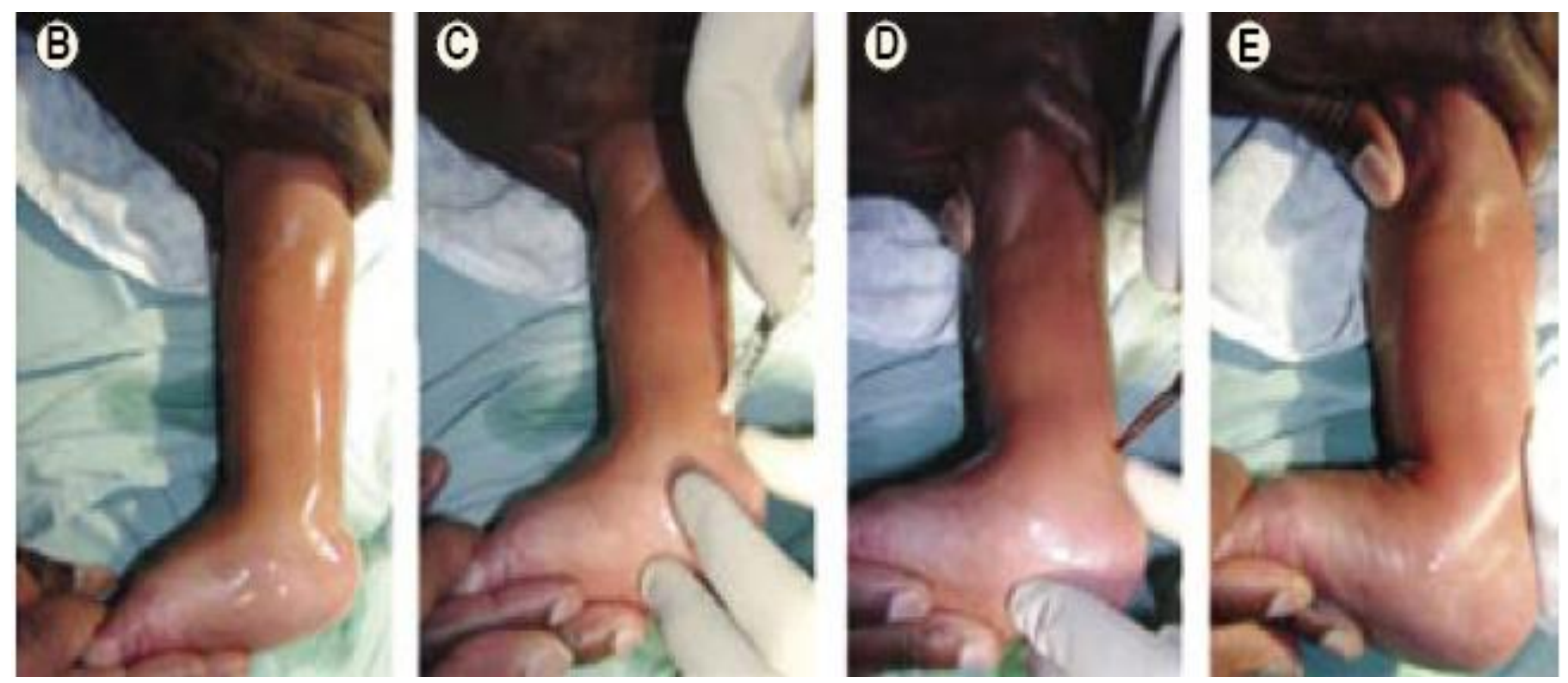

Post tenotomy dorsiflexion of 10 degrees was usually obtained. Post tenotomy cast was applied for 3 weeks. If ankle dorsiflexion of less than 5 degrees was obtained post tenotomy than cast was applied for 1 week only and a new cast was applied weekly with increasing dorsiflexion till 10 degreesof dorsiflexion was obtained. Following cast removal Dennis Brown splint was applied.(Figure 5) Feet were kept at 40 degree abduction on both normal and affected sides unlike standard Ponsetti technique, where feet are kept at 70 degree abduction on affected side and 40 degree abduction on normal side.

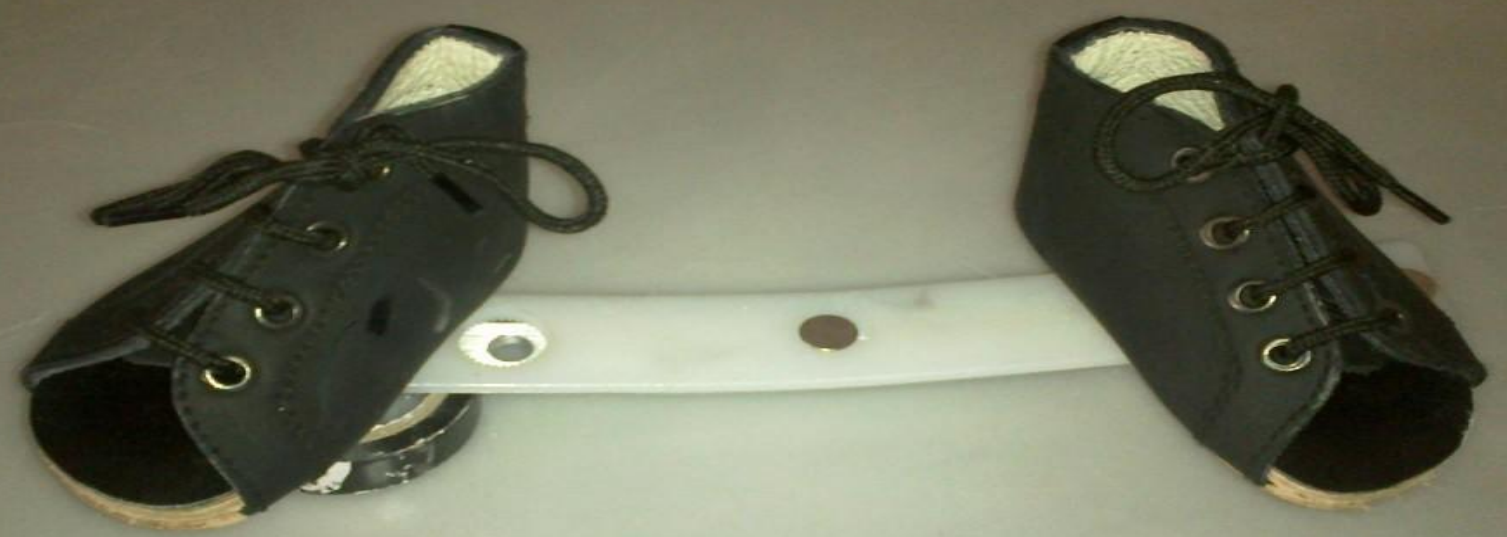

Brace was applied for 23 hours for first 3 months. Following initial 3 months in brace,weaning from brace was done with 2 hours of bracing time reduced every month until night time bracing (12 hours) was started and was advised to be kept for 3-4 years. 


\section{Results:-}

The average age of the patients at the start of treatment was 3 months(range, 1-5 months). All the twenty patients had unilateral clubfoot.The mean number of cast that were applied to obtain correction was 8 (range four to nine casts). Percutaneous tendo Achilles tenotomy to correct the residual equinus deformity was done in all patients .The average follow-up was for 1 and half years (range 1 to 3 years). Finally, all feet were corrected (figure 5) with mean ankle dorsiflexion of $15^{\circ}$ (range, $10^{\circ}-20^{\circ}$ ).

\section{Discussion:-}

Orthopaedicians have been treating clubfoot successfully using Ponseti technique (Chotel et al.,2002; Colburn and Williams, 2003). However there is a small group of clubfoot which does not correct or shows resistance to correction by standard Ponseti method. These feet are short and stubby. The hindfoot is in severe equinus and varus .The calf muscles are small and the tendo achilles is long, wide, and tight. The forefoot is adducted and all metatarsals are in severe plantar flexion. There is a deep crease across the sole of the foot and another above the heel. The great toe is short and in dorsiflexion. Applying casts by standard Ponseti methods leads to complex deformities in these cases. There develops hyperabduction of forefoot at tarso-metatarsal joint but caves and equinus do not get corrected. There occurs slippage of cast causing sores over bony prominences and edema of the foot. This type of clubfoot is difficult to treat and requires modified Ponseti technique. Adduction of forefeet should not be corrected beyond 40 degrees to prevent hyperabduction at tarso-metatarsal joint. Adduction should be corrected by keeping thumb on lateral aspect of talar head and index finger of same hand behind lateral malleolus. This also corrects heel varus. Once the heel varus is corrected, the planter-flexed forefoot and the equinus are corrected simultaneously by forcefully dorsiflexing the metatarsals with both thumbs while keeping index fingers of both thumbs on dorsal aspect of talar head. The cast is strengthened by applying a posterior slab behind the ankle. To prevent the cast from slipping, knee is immobilized at 110 degrees of flexion and it is strengthened with a slab applied anteriorly over the knee. A tenotomy is performed before applying the last plaster cast to facilitate correction of any unyielding equinus.

Thus our study shows that an orthopaedic surgeon needs to be careful enough to identify an atypical clubfoot. There is need of modified Ponseti technique in case of atypical clubfeet.This modification corrects the deformity thus decreasing the need for surgery in most children. Once an atypical clubfoot is treated adequately, the foot develops normally.

\section{Bibliography:-}

1. Chotel F, Parot R, Durand JM, Garnier E, Hodgkinson I, Berard J. Initial management of congenital varusequinus clubfoot by Ponseti's method. Rev ChirOrthopReparatriceAppar Mot. 2002;88:710-717.

2. Colburn M, Williams M. Evaluation of the treatment of idiopathic clubfoot by using the Ponseti method. J Foot Ankle Surg. 2003;42: 259-267.

3. Ponseti IV, Zhivkov M, Davis N, Sinclair M, Dobbs MB, Morcuende JA. Treatment of the complex idiopathic clubfoot. ClinOrthopRelat Res. 2006;451:171-176. doi: 10.1097/01.blo.0000224062.39990.48.

4. Turco V. Recognition and management of the atypical idiopathic clubfoot. In: Simons GW, ed. The Clubfoot: The Present and a View of the Future. New York, NY: Springer-Verlag; 1994:76-77. 